\title{
Immunological mechanism of low-dose priming radiation resistance in walker-256 tumor model mice
}

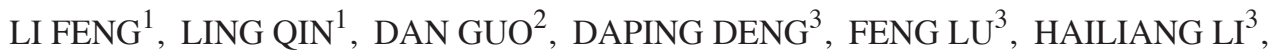 \\ NARISU BAO ${ }^{4}$, XITING YANG ${ }^{4}, \mathrm{HONGYU} \mathrm{DING}^{1}$ and JIANGUO $\mathrm{LI}^{4,5}$ \\ ${ }^{1}$ Ultrasound Department, Qianfoshan Hospital of Shandong, Jinan, Shandong 250014; ${ }^{2}$ Graduate Department, Taishan \\ Medical University, Taian, Shandong 271016; ${ }^{3}$ Laboratory of Radiation Biology, The Radiation Medical Institute, \\ Shandong Academy of Medical Sciences, Jinan, Shandong 250062; ${ }^{4}$ Department of Human Anatomy, The School of \\ Medicine of Inner Mongolia University for The Nationalities, Tongliao, Inner Mongolia 028041; ${ }^{5}$ The Key Laboratory \\ of Bioactive Materials, Ministry of Education, School of Medicine, Nankai University, Tianjin 300071, P.R. China
}

Received November 4, 2016; Accepted June 8, 2017

DOI: $10.3892 /$ etm.2017.4975

\begin{abstract}
The aim of the present study was to investigate whether low-dose priming radiation induces antitumor immunity that can be augmented by the modulation of natural killer (NK) cell and cytokine activity using a mouse tumor model. Walker-256 cells were injected into the right flank of male $\mathrm{BALB} / \mathrm{c}$ mice. At 7 days after inoculation, mice were divided into three groups, including group 1,2,3. In group 1 the mice were without radiation, in group 2 the mice were received 2 Gy radiation only, and in group 3 the mice were radiated with a priming dose of $75 \mathrm{mGy}$ followed by 2 Gy radiation after $24 \mathrm{~h}$. On day 21 following the radiation, the tumors were removed and the tumor index (tumor weight as a percentage of body weight) was calculated. At 1, 7, 14 and 21 days following the 2 Gy radiation, mouse splenocytes were isolated to analyze the NK activity and measure the production of the cytokines interleukin-1 $\beta$, interferon- $\gamma$ and tumor necrosis factor- $\alpha$ by ELISA. Apoptosis was also measured by flow cytometry. The results demonstrated that priming radiation significantly delayed the tumor growth and prolonged the median survival time to 38 days compared with the 31-day survival in the 2 Gy radiation group. The percentage of apoptotic cells was significantly higher in the mice that received $75 \mathrm{mGy}+2$ Gy radiation compared with that in the mice that received 2 Gy alone; by contrast, mice that were not irradiated exhibited a relatively low
\end{abstract}

Correspondence to: Professor Hongyu Ding, Ultrasound Department, Qianfoshan Hospital of Shandong, 16766 Jingshi Road, Jinan, Shandong 250014, P.R. China

E-mail: qqddf11998@163.com

Dr Jianguo Li, Department of Human Anatomy, The School of Medicine of Inner Mongolia University for The Nationalities, 536 Huolinhe Street, Tongliao, Inner Mongolia 028041, P.R. China E-mail: ljg7111@126.com

Key words: low-dose radiation, natural killer activity, cytokines, apoptosis, antitumor, radiation resistance level of apoptosis. The primed mice had a higher level of NK activity as compared with the mice exposed to 2 Gy radiation only or mice that were not irradiated. Furthermore, cytokine expression remained at a higher level in mice receiving priming dose of radiation compared that in the mice receiving only 2 Gy radiation. In conclusion, the results indicated that low-dose priming X-ray radiation may enhance the NK activity and the levels of cytokines, and that the immune response serves an important role in anticancer therapy, including radiotherapy.

\section{Introduction}

Radiotherapy and antitumor immunity have been reported to be closely associated (1). Suzuki et al (2) demonstrated that antitumor responses may be induced in patients with esophageal cancer during and following chemoradiotherapy. In addition, Demaria et al (3) used a mouse syngeneic mammary carcinoma model to indicate that antitumor effects resulted from irradiation-activated antitumor immunity. The abscopal effect is a well-known, but rare clinical phenomenon (3), which is considered to be mediated by the activation of antitumor immunity.

High-dose radiation is known to lead to carcinogenicity and immune function suppression; however, low-dose radiation may have the opposite effect, stimulating immune system functions. In recent decades, various experimental and epidemiological data have demonstrated that exposure to low doses of low-linear energy transfer (LET) radiation can trigger the mechanisms of natural immune surveillance $(4,5)$. Immune responses have been identified to be upregulated in inhabitants of areas with high background radiation (6). Borzoueisileh et al (7) confirmed that, in individuals living in conditions of high background radiation, the percentages of $\mathrm{CD}^{+}$cells gradually increased. There is evidence to suggest that low-dose ionizing radiation may have an immune-stimulatory effect, and that it may induce a certain degree of suppression of tumor metastases and growth $(8,9)$. Cheda et al (10) reported that BALB/c mice implanted with Walker-256 cells presented significantly reduced numbers of pulmonary tumor colonies when the animals were exposed to 
0.1 or 0.2 Gy X-rays. Furthermore, Mitchel et al (11) examined the tumor incidence in heterozygous p53-deficient $\left(\mathrm{p} 53^{+-}\right)$ mice exposed to small daily radiation doses 5 days per week for 30-90 weeks, receiving a total dose of 48, 97 or $146 \mathrm{mGy}$. Their results indicated that low-dose exposure may inhibit the development of tumors. Taken together, the aforementioned observations indicate that low-dose radiation may induce an immune response.

In the current study, a mouse tumor model was used to examine whether low-dose priming radiation served an important role in anticancer therapy, and to investigate whether this antitumor effect resulted from the stimulation of natural killer (NK) lymphocytes, tumor necrosis factor (TNF)- $\alpha$ or other cytokines.

\section{Materials and methods}

Animals. Male BALB/c mice (6 weeks old) with an average body weight of 20-22 g were provided by the Animal Center of Shandong University (Jinan, China). All mice had free access to water and food and were kept in a room maintained at $60 \pm 10 \%$ relative humidity and $20 \pm 2^{\circ} \mathrm{C}$ with a 12 -h light/dark cycle. The mice were acclimated for 7 days prior to experimentation. The animal protocol was reviewed and approved by the Institutional Animal Care and Use Committee of the Radiation Medical Institute, Shandong Academy of Medical Sciences (Jinan, China).

Tumor growth, radiation exposure and survival analysis. Walker-256 cells were supplied by the Military Academy of Medical Sciences (Beijing, China), and the cells were grown at $37^{\circ} \mathrm{C}, 60 \pm 10 \%$ relative humidity and $5 \% \mathrm{CO}_{2}$ for $48 \mathrm{~h}$ in a culture medium composed of the RPMI-1640 medium San Diego, CA, USA) supplemented with $10 \%$ fetal bovine serum (Biomiga, Inc.), $100 \mathrm{U} / \mathrm{ml}$ penicillin, $100 \mu \mathrm{g} / \mathrm{ml}$ streptomycin and $2 \mathrm{mM}$ l-glutamine and stabilized with $\mathrm{Na}_{2} \mathrm{CO}_{3}$. Subsequently, $2.5 \times 10^{7}$ cells were injected into the right flank of the mice in order to establish a tumor model. Approximately 7 days following the inoculation, the tumors became visible and the mice received radiation treatment. A total of 81 mice were randomly divided into three groups $(27$ mice in each group), including the control group (group 1) that was not exposed to radiation. In the 2 Gy radiation group (group 2), the mice received only a high dose of $2 \mathrm{~Gy}(100 \mathrm{cGy} / \mathrm{min})$. In the $75 \mathrm{mGy}+2$ Gy radiation group (group 3), mice received a low dose of $75 \mathrm{mGy}(0.1 \mathrm{cGy} / \mathrm{min})$ priming radiation, followed by exposure of the local tumor to $2 \mathrm{~Gy}(100 \mathrm{cGy} / \mathrm{min})$ radiation after $24 \mathrm{~h}$ from a Primus High Energy medical electron linear accelerator (Siemens, Jinan, China). The tumors were exposed to 2 Gy X-rays at a dose rate of $1.0 \mathrm{~Gy} / \mathrm{min}$ and the rest of the body was shielded by lead.

For determination of the tumor index, the tumors $(n=5$ per group) were removed and measured using an electronic balance on day 21 following radiation treatment. The tumor index was calculated using the following formula: Tumor index $(\%)=($ tumor weight/body weight) $\mathrm{x} 100$. In order to avoid a possible effect on the study outcome, mice that died during the course of the radiation exposure were excluded. The survival analysis of the mice was thus restricted to mice that were alive upon completion of their respective full-dose exposures.
Flow cytometric analysis of apoptosis. The tumors were removed, ground and plated on days 1, 7, 14 and 21 following the 2 Gy radiation ( 5 mice per group at each time point). The obtained cells were washed with phosphate-buffered saline and suspended with ethylenediaminetetraacetic acid. Floating cells were also collected by centrifugation at $1,000 \mathrm{x} \mathrm{g}$ for $20 \mathrm{~min}$ at $20 \pm 2^{\circ} \mathrm{C}$, and the total cell population was analyzed. Cell surface Annexin V was detected by flow cytometry using the ApoAlert Annexin V kit (Clontech Laboratories, Inc., Mountain View, CA, USA) as described in the manufacturer's instructions, and a BD LSR II flow cytometer (BD Biosciences, Franklin Lakes, NJ, USA). Briefly, the cells were washed in $1 \mathrm{X}$ binding buffer (Biomiga Company, USA), collected by centrifugation at $1,000 \mathrm{x}$ g for $15 \mathrm{~min}$ at $20 \pm 2^{\circ} \mathrm{C}$ and then resuspended in $200 \mu \mathrm{l} 1 \mathrm{X}$ binding buffer containing Annexin $\mathrm{V}(0.1 \mu \mathrm{g} / \mathrm{ml})$ and propidium iodide $(0.5 \mu \mathrm{g} / \mathrm{ml})$. Following incubation at $20 \pm 2^{\circ} \mathrm{C}$ for $15 \mathrm{~min}$, the cells were analyzed by flow cytometry.

Analysis of cytokine levels by ELISA. Serum was obtained from peripheral blood samples by centrifugation at $1,500 \mathrm{xg}$ for $10 \mathrm{~min}$ at $4^{\circ} \mathrm{C}$ and immediately frozen at $-80^{\circ} \mathrm{C}$ for further analysis. Interleukin (IL) $-1 \beta$, interferon (IFN) $-\gamma$ and TNF- $\alpha$ levels in the serum were then measured using mouse IL-1 $\beta$, IFN- $\gamma$ and TNF- $\alpha$ ELISA kits (MWSP10, MX000 and MRGMA0; R\&D Systems, Inc., Minneapolis, MN, USA), according to the manufacturer's instructions (12).

NK cell activity assay by $L D H$. The human erythroleukemia K-562 cell line (Chinese Academy of Sciences, Shanghai, China) was used as the control cells in this assay. Briefly, K-562 cells were cultured in RPMI-1640 medium supplemented with $10 \%$ fetal bovine serum (Hyclone; GE Healthcare Life Sciences, Logan, UT, USA) and then plated at a concentration of 1x105 cells/ml in U-bottom 96-well plates (Corning, Inc., Shanghai, China). Murine spleens were harvested and extracted by centrifugation at $1,000 \mathrm{x}$ for $10 \mathrm{~min}$ at $20 \pm 2^{\circ} \mathrm{C}$, and splenocytes were plated at $1 \times 10^{5}$ cells $/ \mathrm{ml}$ for an effector to target ratio of 50:1 on day 2 post radiation. The cytotoxic activity of NK cells in each of these groups used from the mice splenocytes was measured at the same day using a standard in vitro lactate dehydrogenase (LDH) release assay as previously described (13). The plates were incubated for $20 \mathrm{~h}$ at $37^{\circ} \mathrm{C}$ and $5 \% \mathrm{CO}_{2}$, and then centrifuged for $5 \mathrm{~min}$ at $1,000 \mathrm{x}$ g at $20 \pm 2^{\circ} \mathrm{CC}$. Subsequently, $100 \mu \mathrm{l}$ supernatant was moved to a new plate, followed by addition of $100 \mu \mathrm{l}$ LDH kit (P1240; R\&D Systems, Inc.) and $30 \mu 1 \mathrm{HCl}(1 \mathrm{M})$ to each well. Finally, the optical density (OD) was measured using an Infinite M200 PRO automatic microplate reader (Tecan Group Ltd., Männedorf, Switzerland) at a wavelength of $490 \mathrm{~nm}$. The percentage of cytotoxicity was calculated using the following formula: Cytotoxicity $(\%)=($ sample OD-spontaneous OD)/(maximum OD-spontaneous OD) x100 (13).

Statistical analysis. Data are presented as the mean \pm standard deviation. Data were analyzed using one-way analysis of variance with a post hoc Tukey's test (multiple comparison test), which determined the significant differences among groups. $\mathrm{P}<0.05$ was considered to indicate a statistically significant 


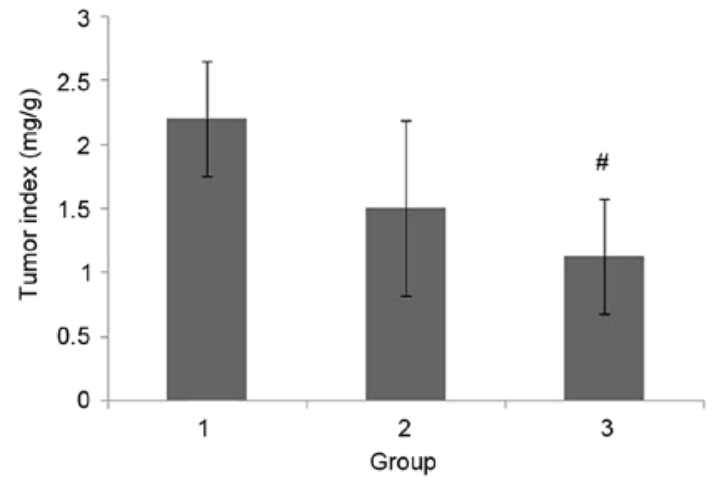

Figure 1. Effect of radiation on the growth of tumors in mice. The effect is presented in term of the tumor index $(\mathrm{mg} / \mathrm{g})$ at day 21 after tumor induction. Group 1 comprises of mice with no exposure, group 2 comprises mice exposed to 2 Gy radiation, and group 3 comprises mice exposed to priming $75 \mathrm{mGy}+2$ Gy radiation. Data are presented as the mean \pm standard deviation (8 mice were in each group). ${ }^{\#} \mathrm{P}<0.05$ vs. group 2 .

difference. SPSS Version 13.0 software (SPSS, Inc., Chicago, IL, USA) was used for analysis.

\section{Results}

Effects of radiation on survival time. The survival time was calculated from the day when tumor cells were injected. The median survival time of the mice in group 1 was 20 days. By contrast, the median survival time of the mice in group 2 was 31 days, while that of mice in group 3 was 38 days. An evident difference in the median survival time was observed between the 3 groups and there was significant difference between groups 1 and 2, 3 (the $2 \mathrm{~Gy}$ and the $75 \mathrm{mGy}+2$ Gy radiation groups; $\mathrm{P}<0.05$ ), however, no statistical difference was noted between the groups 2 and $3(\mathrm{P}>0.05)$.

Effects of radiation on antitumor activity. On day 21 following radiation, low-dose priming radiation significantly increased the antitumor efficacy of the subsequent high-dose radiation, the tumor index was $2.21 \pm 0.45$ in group $1,1.51 \pm 0.69$ in group 2 and $1.13 \pm 0.32$ in group 3 . Furthermore, the tumor index in mice was significantly lower in group 3 compared with that in group 2 mice $(\mathrm{P}<0.05$; Fig. 1). Thus, these results demonstrated that the $75 \mathrm{mGy}$ priming radiation led to a significant inhibitory effect on tumor growth.

Effects of radiation on apoptosis. The early apoptotic cells were assayed on days 1, 7, 14 and 21 following radiation. In primed mice, the proportion of early apoptotic cells increased to $16.5 \%$ on day 7 following radiation, and then further increased to $18.8 \%$ of the total cells on day 14 and $22.63 \%$ on day 21 (Fig. 2). The percentage of apoptotic cells was significantly higher in the primed mice in comparison with that in the mice irradiated with $2 \mathrm{~Gy}$ alone. These data indicate that addition of a priming dose of radiation exerted a greater suppressive effect on tumors through the induction of apoptosis when compared with radiation with 2 Gy alone. Furthermore, the percentage of apoptotic cells was significantly lower in mice that were not irradiated as compared with that in mice treated with a priming dose of radiation ( $\mathrm{P}<0.05$; Fig. 2).

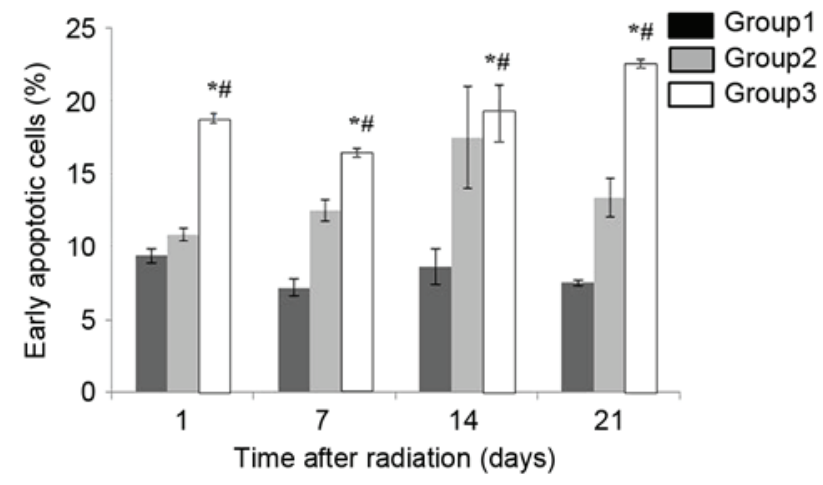

Figure 2. Effect of radiation on apoptosis in terms of the percentage of cell apoptotic cells. Group 1 represents tumor model mice with no exposure to radiation, group 2 represents mice exposed to 2 Gy radiation and the group 3 represents mice exposed to 75 priming $\mathrm{mGy}+2 \mathrm{~Gy}$ radiation. Data are presented as the mean \pm standard deviation $(5$ mice were in each group at each time point). ${ }^{*} \mathrm{P}<0.05$ vs. group $1 ;{ }^{\#} \mathrm{P}<0.05$ vs. group 2 .

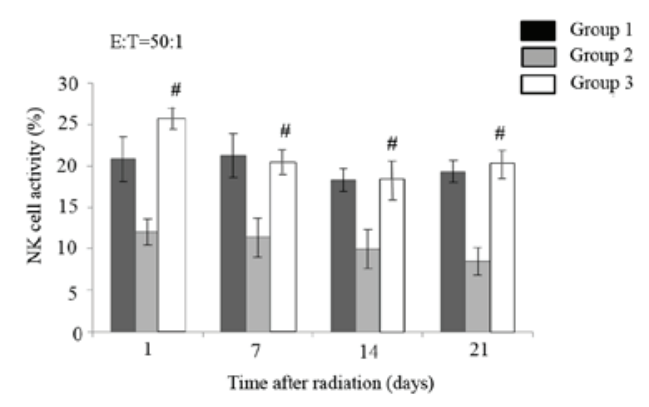

Figure 3. NK cell activity in the tumor model mice treated with radiation. Group 1 represents tumor model mice with no exposure, group 2 represents mice exposed to $2 \mathrm{~Gy}$ and group 3 represents mice exposed to priming $75 \mathrm{mGy}+2$ Gy. Data are presented as the mean \pm standard deviation ( 5 mice were in each group at each time point). ${ }^{\#} \mathrm{P}<0.05$ vs. group 2 . E:T, effector cells:target cells; NK, natural killer.

Effects of radiation on $N K$ cell activity by $L D H$ assay. NK cell activity in the spleens of mice in the three groups was tested on days 1, 7, 14 and 21 after radiation by LDH assay. The effects of priming with a low dose of radiation on the spleen-derived NK cell activity in the mice are shown in Fig. 3. The NK-type activity in group 2 decreased in response to radiation, and the NK cell activity decreased in group 3 from day 1 to 14 post radiation and increased at day 21 (Fig. 3). Furthermore, statistical analysis indicated that NK cell activity was significantly higher in the $75 \mathrm{mGy}+2$ Gy radiation group when compared with that in the 2 Gy radiation group ( $\mathrm{P}<0.05$; Fig. 3 ).

Effects of radiation on cytokine levels. The cytokine levels in mice that were not irradiated were considered as the control levels. In the $2 \mathrm{~Gy}$ radiation group, the production of IL-1 $\beta$ was downregulated on the first day following radiation, with no significant difference observed compared with the control levels (Fig. 4). By contrast, in the mice that received priming radiation, the production of IL-1 $\beta$ was significantly enhanced from day 1 post exposure and gradually declined by day 21 , although the expression remained elevated. The level of IL-1 $\beta$ in the primed mice was higher compared with that of mice in the 2 Gy radiation and control groups $(\mathrm{P}<0.05)$. Similarly, 

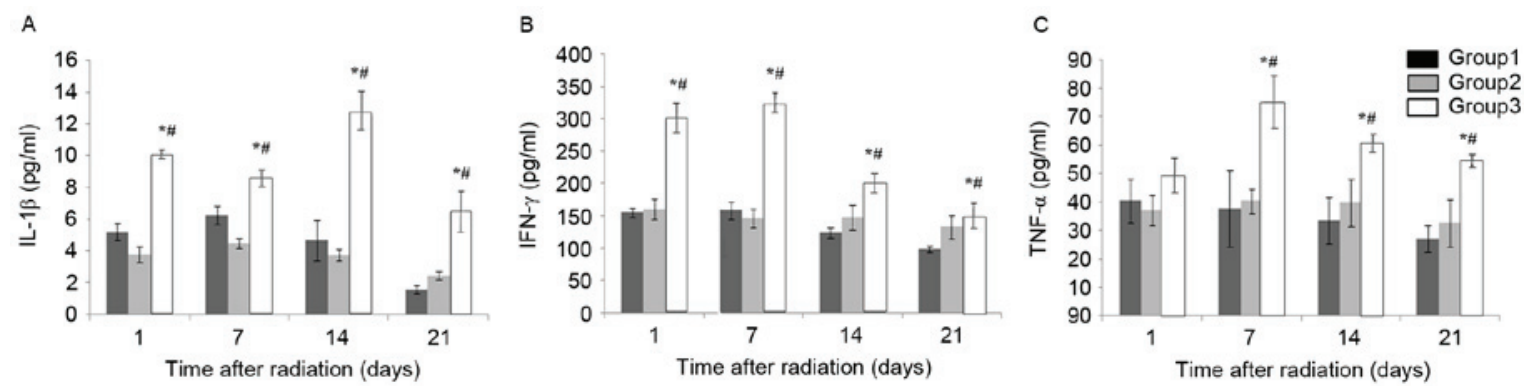

Figure 4. Cytokine expression levels in the peripheral blood of tumor model mice exposed to radiation. Alterations in the (A) IL-1 $\beta$, (B) IFN- $\gamma$ and (C) TNF- $\alpha$ expression levels are shown. Group 1 represents tumor model mice with no exposure, group 2 represents mice exposed to 2 Gy and group 3 represents mice were exposed to priming $75 \mathrm{mGy}+2 \mathrm{~Gy}$. Data are presented as the mean \pm standard deviation $\left(5\right.$ mice were in each group at each time point). ${ }^{*} \mathrm{P}<0.05$ vs. group 1; ${ }^{\text {P }}<0.05$ vs. group 2 . IL, interleukin; IFN, interferon; TNF, tumor necrosis factor.

the production of TNF- $\alpha$ was also increased on day 1 postradiation in the primed mice and remained elevated until day 21 post radiation. This increased level of TNF- $\alpha$ in mice receiving a priming dose of radiation was significantly higher in comparison with that in the other mouse groups $(\mathrm{P}<0.05$; Fig. 4). Furthermore, the production of IFN- $\gamma$ in the primed mice was upregulated on day 1 post radiation and reached a peak level on day 7 , after which it gradually declined but remained elevated. The increased level of IFN- $\gamma$ in primed mice was markedly higher compared with that in the other mice $(\mathrm{P}<0.05)$. Therefore, the results revealed that $75 \mathrm{mGy}$ $\mathrm{X}$-ray priming radiation induced a significant enhancement of the production of IL-1 $\beta$, TNF- $\alpha$ and INF- $\gamma$ (Fig. 4). The changes of the TNF- $\alpha$ and IFN- $\gamma$ levels were in good agreement with the changes in the NK cell activity (Fig. 4).

\section{Discussion}

In the present study, treatment with 2 Gy radiation or with $75 \mathrm{mGy}+2$ Gy radiation resulted in tumor indices of $1.51 \pm 0.69$ and $1.13 \pm 0.32$, respectively, on day 21 . The median survival time extended from 31 days in the 2 Gy radiation group to 38 days in the $75 \mathrm{mGy}+2$ Gy radiation group. The results demonstrated that the $75 \mathrm{mGy}$ priming radiation significantly elevated the therapeutic efficacy of the radiation in terms of tumor growth inhibition and survival time. This suggests that 75 mGy priming radiation induced immune responses, which were essential for the local control of tumors. The current results are consistent with an acute high- and low-dose-rate priming dose observed in previous studies of the radioadaptive response (14-16). Other previous studies have observed that the priming radiation at a high-dose rate may even evoke a radioadaptive response several $\mathrm{h}$ prior to the administration of the challenging irradiation $(17,18)$.

In the present study, the results revealed that the percentage of apoptotic cells was significantly higher in the primed mice as compared with that in the mice irradiated with 2 Gy alone. These data indicate that the priming dose followed by 2 Gy radiation exerted greater suppressive effects on tumor cells by the induction of higher apoptosis as compared with that caused by radiation with 2 Gy alone. A previous study reported that, in mice treated with 0.05 Gy priming radiation, the frequency of radioresistance significantly increased and persisted for 2-2.5 months. However, radiation priming with $0.30 \mathrm{~Gy}$ and
$0.50 \mathrm{~Gy}$ resulted in radioresistance 2 weeks later, but this radioresistance was no longer observed 2 months later (19). The results indicated that the biological effects of ionizing radiation may be distinguished with the different priming radiation dose, which may be further investigated in future studies. In the current some study, it has been demonstrated that the protective inhibitory effect of a $75 \mathrm{mGy}$ priming dose on the level of apoptosis persisted for $\geq 21$ days; thus, the radio-adaptive-response may depend on the priming dose. A study by Sasaki (14) indicated that X-ray doses of $>0.1$ or $<0.1$ Gy appeared to be recognized as different signals; higher doses of X-rays were incapable of inducing adaptation and rapidly extinguished the adapted condition.

The cytotoxic capacity of immune cells, particularly NK activity, serves a key role in immune surveillance, and these cells also produce a variety of regulatory cytokines that exert inhibitory effects on tumor growth (20). Primary cellular effectors of the non-specific antitumor surveillance system include NK lymphocytes. In the present study, it was demonstrated that the priming dose of radiation in mice led to significant protection of the NK cytotoxic function, with the enhanced cytotoxicity being the most pronounced on day 21 . The NK cell activity was significantly higher in the priming radiation group when compared with that in the 2 Gy radiation group. The results of the present study, which demonstrated that a low-dose of priming radiation was able to trigger the NK cytotoxic function, suggested that the therapeutic efficacy may be increased by the augmentation of NK cytotoxic function. The present and previous study results confirmed that stimulation of the antineoplastic immune surveillance was mediated by NK lymphocytes, at least partially, and the accumulating experimental evidence indicated that low-level exposure to low LET radiation inhibited tumor development $(21,22)$.

Cytokines are important regulators of the immune response that are involved in maintaining the balance of the immune system. Following the triggering of the adaptive immune system, activated lymphocytes secrete cytokines. In the present study, low-dose priming radiation of mice with $75 \mathrm{mGy} X$-rays significantly stimulated the synthesis of IL-1 $\beta$, TNF- $\alpha$ and IFN- $\gamma$ in the splenocytes of mice. IFN- $\gamma$ is a prominent activator of NK lymphocytes $(23,24)$ and can exert a strong antineoplastic effect $(25,26)$, which is not only directly cytocidal for tumor cells, but also stimulates the cytolytic functions of macrophages. It has been reported that the 
percentage of T-lymphocyte subsets and their protein levels in the supernatant were significantly increased at $24 \mathrm{~h}$ after exposure to $0.05 \mathrm{~Gy}{ }^{12} \mathrm{C}^{6+}$ ion irradiation (27). The findings of the current study demonstrated that, in mice exposed to priming radiation, the production of IL- $1 \beta$ was significantly enhanced and then gradually declined, although it remained elevated. The level of IL-1 $\beta$ production in the $75 \mathrm{mGy}+2$ Gy radiation group was higher compared with that in other groups $(\mathrm{P}<0.05)$. The production of TNF- $\alpha$ and INF- $\gamma$ followed a similar trend to that of IL-1 $\beta$.

The obtained results in the present study indicated that $75 \mathrm{mGy}$ X-ray priming radiation induced significant enhancements in the production of IL- $1 \beta$, TNF- $\alpha$ and INF- $\gamma$ (Fig. 4). The present results are consistent with the observations of previous studies, although the doses used and the timing of the effects observed in the previous studies may differ from the present findings. For instance, Zhang et al (28) detected an increased content of IL-1 $\beta$ in Kunming mice pre-irradiated with X-ray doses ranging between 0.05 and 0.25 Gy. Ibuki and Goto (29) also observed that irradiation of C57BL/6 mice with a single 0.04-Gy dose of $\gamma$-rays markedly stimulated the production of IFN- $\gamma$ by splenocytes isolated at $4 \mathrm{~h}$ following the exposure. In addition, when C57BL/6 mice were irradiated with 0.075 Gy $\mathrm{X}$-rays at $24 \mathrm{~h}$ prior to the injection of Lewis lung carcinoma cells, the splenic secretion of IFN- $\gamma$ was elevated on days 2-8 following the exposure (30). Furthermore, Bai et al (31) and Gong et al (32) demonstrated that the production of IFN- $\gamma$ in splenocytes was significantly increased at $24 \mathrm{~h}$ following the whole-body irradiation of mice with 0.075 Gy X-rays.

In conclusion, the current results indicate that low-dose priming X-ray radiation may enhance the NK activity and cytokine levels in tumor-bearing mice, and significantly inhibits the development of experimental tumors. However, further studies are required to explore whether other immune cells and/or reactions are also involved in radioresistance effects of low-dose priming X-ray radiation. Furthermore, the upper and lower dose limits of the above effects and the possible practical applicability should also be investigated in future studies.

\section{Acknowledgements}

The authors are grateful to the National Natural Science Foundation of China (grant no. 81760567), the Natural Science Foundation of Shandong (grant no. ZR2014Y1027) and the Natural Science Foundation of Inner Mongolia Autonomous Region of China (grant no. 2016MS0814) for funding the present study.

\section{References}

1. Shahabi V, Postow MA, Tuck D and Wolchock JD: Immune-priming of the tumor microenvironment by radiotherapy: Rationale for combination with immunotherapy to improve anticancer efficacy. Am J Clin Oncol 38: 90-97, 2015.

2. Suzuki Y, Mimura K, Yoshimoto Y, Watanabe M, Ohkubo Y, Izawa S, Murata K, Fujii H, Nakano T and Kono K: Immunogenic tumor cell death induced by chemoradiotherapy in patients with esophageal squamous cell carcinoma. Cancer Res 72: 3967-3976, 2012.

3. Demaria S, Ng B, Devitt ML, Babb JS, Kawashima N, Liebes L and Formenti SC: Ionizing radiation inhibition of distant untreated tumors (abscopal effect) is immune mediated. Int J Radiat Oncol Biol Phys 58: 862-870, 2004.
4. Hashimoto S, Shirato H, Hosokawa M, Nishioka T, Kuramitsu Y, Matushita K, Kobayashi M and Miyasaka K: The suppression of metastases and the change in host immune response after low-dose total-body irradiation in tumor-bearing rats. Radiat Res 151: 717-724, 1999.

5. Ito M, Shibamoto Y, Ayakawa S, Tomita N, Sugie C and Ogino H: Effect of low-dose total-body irradiation on transplantability of tumor cells in syngeneic mice. J Radiat Res 49: 197-201, 2008.

6. Safwat A: The immunobiology of low-dose total-body irradiation: More questions than answers. Radiat Res 153: 599-604, 2000.

7. Borzoueisileh S, Monfared AS, Abediankenari S, Mostafazadeh A and Khosravifarsani M: The effects of residence duration in high background radiation areas on immune surveillance. J Nat Sci Biol Med 4: 218-222, 2013.

8. Sakamoto K, Miyamoto M and Watabe N: The effect of small-dose total body irradiation on tumor control. Gan To Kagaku Ryoho 14: 1545-1549, 1987 (In Japanese).

9. Hosoi Y and Sakamoto K: Suppressive effect of low dose total body irradiation on lung metastasis: Dose dependency and effective period. Radiother Oncol 26: 177-179, 1993.

10. Cheda A, Wrembel-Wargocka J, Lisiak E, Lisiak E, Nowosielska EM, Marciniak M and Janiak MK: Single low doses of $\mathrm{X}$ rays inhibit the development of experimental tumor metastases and trigger the activities of NK cells in mice. Radiat Res 161: 335-340, 2004

11. Mitchel RE, Burchart P and Wyatt H: A lower dose threshold for the in vivo protective adaptive response to radiation. Tumorigenesis in chronically exposed normal and Trp53 heterozygous C57BL/6 mice. Radiat Res 170: 765-775, 2008.

12. Cheda A, Nowosielska EM, Wrembel-Wargocka J and Janiak MK: Production of cytokines by peritoneal macrophages and splenocytes after exposures of mice to low doses of X-rays. Radiat Environ Biophys 47: 275-283, 2008.

13. Fu Y, Zhang Y, Chang X, Zhang Y, Ma S, Sui J, Yin L, Pu Y and Liang G: Systemic immune effects of titanium dioxide nanoparticles after repeated intratracheal instillation in rat. Int J Mol Sci 15: 6961-6973, 2014.

14. Okazaki R, Ootsuyama A and Norimura T: Radioadaptive response for protection against radiation-induced teratogenesis. Radiat Res 163: 266-270, 2005.

15. Sasaki MS: On the reaction kinetics of the radioadaptive response in cultured mouse cells. Int J Radiat Biol 68: 281-291, 1995.

16. Chen Z and Sakai K: Enhancement of radiation-induced apoptosis by preirradiation with low-dose X-rays in human leukemia MOLT-4 cells. J Radiat Res 45: 239-243, 2004.

17. Newman MR, Sykes PJ, Blyth BJ, Bezak E, Lawrence MD, Morel KL and Ormsby RJ: A single whole-body low dose $\mathrm{X}$-irradiation does not affect L1, B1 and IAP repeat element DNA methylation longitudinally. PLoS One 9: e93016, 2014.

18. Okazaki R, Ootsuyama A and Norimura T: TP53 and TP53-related genes associated with protection from apoptosis in the radioadaptive response. Radiat Res 167: 51-57, 2007.

19. Yonezawa M, Misonoh J and Hosokawa Y: Two types of X-ray induced radioresistance in mice: Presence of 4 dose ranges with distinct biological effects. Mutat Res 358: 237-243, 1996.

20. Perussia B: Lymphokine-activated killer cells, natural killer cells and cytokines. Curr Opin Immunol 3: 49-55, 1991.

21. Nowosielska EM, Cheda A, Wrembel-Wargocka J and Janiak MK: Immunological mechanism of the low-dose radiation-induced suppression of cancer metastases in a mouse model. Dose Response 8: 209-226, 2019.

22. Avogadri F, Mittal D, Saccheri F, Sarrafiore M, Ciocca M, Larghi P, Orecchia R and Rescigno M: Intra-tumoral Salmonella typhimurium induces a systemic anti-tumor immune response that is directed by low-dose radiation to treat distal disease. Eur J Immunol 38: 1937-1947, 2008.

23. Kosaka A, Yan H, Ohashi S, Gotoh Y, Sato A, Tsutsui H, Kaisho T, Toda T and Tsuji NM: Lactococcus lactis subsp. cremoris FC triggers IFN- $\gamma$ production from NK and T cells via IL-12 and IL-18. Int Immunopharmacol 14: 729-733, 2012.

24. Sieve AN, Meeks KD, Lee S and Berg RE: A novel immunoregulatory function for IL-23: Inhibition of IL-12-dependent IFN- $\gamma$ production. Eur J Immunol 40: 2236-2247, 2010.

25. al-Sarireh B, Eremin O: Tumour-associated macrophages (TAMS): Disordered function, immune suppression and progressive tumour growth. J R Coll Surg Edinb 45: 1-16, 2000.

26. Belardelli F and Ferrantini M: Cytokines as a link between innate and adaptive antitumour immunity. Trends Immunol 23: 201-208, 2002. 
27. Chen Y, Chen X, Li Y, Zhang H, Xie Y, Zhang X, Ren H, Wang Y, Liao S and He M, et al: Early effects of low dose C ion or X-ray irradiation on peripheral blood lymphocytes of patients with alimentary tract cancer. Dose Response 9: 356-368, 2011.

28. Zhang M, Chen Z and Liu SZ: Effects of low dose irradiation on the splenic macrophage function in mice. Baiqiuen Yike Daxue Xuebao 22: 131-133, 1996 (In Chinese).

29. Ibuki Y and Goto R: Augmentation of NO production and cytolytic activity of $\mathrm{M}$ phi obtained from mice irradiated with a low dose of gamma-rays. J Radiat Res 36: 209-220, 1995.
30. Fu HQ, Li XY, Chen YB, Zhang YC and Liu SZ: Mechanism of suppressive effect of low dose radiation on cancer cell dissemination in mice. J Radiat Res Radiat Process 15: 40-43, 1997.

31. Bai O, Liu SZ and Mu Y: Effect of low dose radiation on Th1 and Th2 of thymocytes and splenocytes in mice. Chin J Radiol Med Prot 18: 106-109, 1998.

32. Gong S, Liu J, Liu S, Zhang Y and Liu S: Effect of splenocyte extracellular fluid irradiated with low dose X-rays on thymocyte apoptosis after larger dose X-irradiation in mice. Radiat Res Radiat Process 15: 36-39, 1997. 